\title{
CUSTEIO BASEADO EM ATIVIDADES E ORÇAMENTO BAESADO EM ATIVIDADES EM UM CASO INDUSTRIAL
}

\section{ACTIVITY-BASED COSTING AND ACTIVITY-BASED BUDGETING IN AN INDUSTRIAL CASE}

\author{
Thiago Coelho Soares ${ }^{1}$ \\ ${ }^{1}$ Universidade do Sul de Santa Catarina - UNISUL - Palhoça - Brasil \\ thiago.soares@unisul.br
}

\begin{abstract}
Resumo
O objetivo deste artigo é mostrar a interação do custeio baseado em atividades com o orçamento baseado em atividades evidenciando um estudo de caso no setor industrial, em um estudo de caso em uma cervejaria. O orçamento baseado em atividades analisa os produtos ou serviços produzidos, que atividades são exigidas para produzir esses produtos ou serviços, e que recursos precisam ser orçados para executar essas atividades. Este processo de elaboração orçamentária identifica o nível de recursos que são necessários para executar as atividades, a relação entre essas atividades e o resultado obtido, e também como mudanças na expectativa dos resultados poderão afetar as atividades correlatas. A realização do estudo de caso, embora com números simplificados, permitiu verificar que o orçamento baseado em atividades pode ser aplicado a todas as atividades da empresa analisada. Também foi possível verificar que a diferença entre o orçamento tradicional e o orçamento baseado em atividades reside no fato do consumo dos recursos ocorrerem por atividades, enquanto naquele os recursos são consumidos pelos centros de custo.
\end{abstract}

Palavras-chave: orçamento baseado em atividade; custeio baseado em atividades; indústria.

\section{Introdução}

Nos dias de hoje, está cada vez mais clara a necessidade de um processo orçamentário eficaz em todos os setores da indústria. Todas as organizações tem que se adaptar a um meio em que a alocação de recursos constitui um desafio cada vez mais sério, com as empresas enfrentando uma queda nos lucros, custos cada vez maiores e pressões cada vez mais fortes para manter os preços baixos.

Para alocar efetivamente recursos limitados, um processo orçamentário tem que dar, ao mesmo tempo, a resposta a duas perguntas: Onde e como gastar o dinheiro da empresa eficazmente? Quanto gastar?

Porém, muitos questionamentos são efetuados pelos gestores no que se refere a real diferença entre os novos modelos e os tradicionais orçamentos que geralmente são elaborados nas empresas. 
Nos orçamentos tradicionais, geralmente não há metas bem definidas e o envolvimento na elaboração do orçamento, restringe-se apenas a alta administração, ou seja, não há uma participação efetiva dos funcionários da empresa. Essas projeções sempre são feitas considerando-se os orçamentos dos anos anteriores e isso normalmente gera como resultado as mesmas falhas e perpetuação dos erros.

Assim, este artigo tem por objetivo mostrar a interação do custeio baseado em atividades com o orçamento baseado em atividades evidenciando um estudo de caso no setor industrial.

\section{Evolução do orçamento}

Segundo Lunkes (2007), o termo orçamento tem sua origem atrelada a uma bolsa de tecido chamada "fiscus" e utilizada pelos antigos romanos para coletar os impostos.

O ser humano necessita orçar desde os seus primórdios. O homem das cavernas necessitava prever a quantidade de alimentos para os longos invernos, desta forma desenvolveu práticas orçamentárias antigas. Existem vestígios de práticas orçamentárias formais mais antigas que a origem do dinheiro. Em empresas, o orçamento foi utilizado primeiramente por Brown, gerente financeiro da Du Pont de Memours, nos Estados Unidos, em 1919 (ZDANOWICZ, 1989).

Como consequência da Revolução Industrial, os proprietários de empresas passaram a direcionar somas significantes de capital para seus processos de produção e a contratarem empregados para longos prazos, objetivando máxima eficiência dos investimentos de capital. Assim, para Johnson e Kaplan (1987) o orçamento empresarial começou a ser necessário e adotado.

Tavares (1991) desenvolveu um panorama comparativo do que ele chama de evolução do Planejamento Estratégico, colocando a Gestão Estratégica como uma prática que veio para resolver problemas de implementação do Planejamento Estratégico.

Segundo Tavares (1991) a década de 1950 foi o período do Planejamento Financeiro. Neste período as organizações desenvolviam orçamentos anuais baseados em receitas previstas, estimando seus gastos. No entanto, muitas organizações privadas e públicas ainda desenvolvem apenas esse tipo de planejamento, que tem por característica que os participantes do orçamento definam os gastos futuros com base no que foi gasto no passado.

Conforme Hansen, Otley e Stede (2003) o orçamento tradicional sido alvo de críticas. Pois além de estabelecer uma metodologia para a preparação, execução e controle de resultado. Todavia a contínua verificação dessas imperfeições na prática orçamentária pode significar a inviabilidade das soluções propostas e, por conseqüência a ineficácia da metodologia. Por esta razão novas formas orçamentárias foram e são elaboradas.

Na sequência é apresentada uma figura para ilustrar a evolução do orçamento ao longo dos tempos. 
Tabela 1: Evolução dos processos orçamentários

\begin{tabular}{|c|c|c|c|c|c|}
\hline 1900 & 1920 & 1970 & 1970 & 1980 & 2000 \\
\hline $\begin{array}{l}\text { Orçamento } \\
\text { Empresarial }\end{array}$ & $\begin{array}{l}\text { Orçamento } \\
\text { Contínuo }\end{array}$ & $\begin{array}{l}\text { Orçamento } \\
\text { Base Zero }\end{array}$ & $\begin{array}{l}\text { Orçamento } \\
\text { Flexível }\end{array}$ & $\begin{array}{l}\text { Orçamenro por } \\
\text { Atividades }\end{array}$ & $\begin{array}{l}\text { Beyond } \\
\text { Budgeting }\end{array}$ \\
\hline $\begin{array}{lr}\text { Projeção } & \text { de } \\
\text { recursos baseado } \\
\text { nos objetivos e o } \\
\text { controle } & \text { por } \\
\text { meio } & \text { do } \\
\text { acompanhamento } \\
\text { pelo } \\
\text { contábeis }\end{array}$ & $\begin{array}{l}\text { Renovação do } \\
\text { período } \\
\text { concluído } \\
\text { acréscimento do } \\
\text { mesmo período } \\
\text { no futuro. }\end{array}$ & $\begin{array}{lr}\text { Projeção } & \text { dos } \\
\text { recursos } & \text { da } \\
\text { estaca zero } & \text { com } \\
\text { justificativa } & \text { para } \\
\text { todos os novos } \\
\text { gastos }\end{array}$ & $\begin{array}{lr}\text { Projeção dos } \\
\text { recursos para } \\
\text { vários níveis de } \\
\text { atividades }\end{array}$ & $\begin{array}{lr}\text { Projeção } & \text { dos } \\
\text { recursos } & \text { nas } \\
\text { atividades } & \text { por } \\
\text { meio } & \text { de } \\
\text { direcoinadores. }\end{array}$ & $\begin{array}{l}\text { Projeção dos } \\
\text { recursos de } \\
\text { forma } \\
\text { descentralizada e } \\
\text { flexível, guiado } \\
\text { por um conjunto } \\
\text { de príncípios. }\end{array}$ \\
\hline
\end{tabular}

Fonte: Lunkes (2007)

Conforme Bornia e Lunkes (2007) na primeira fase do orçamento predominaram o orçamento empresarial com a projeção dos recursos baseado nos objetivos e o controle por meio do acompanhamento dos dados oriundos da contabilidade. A segunda fase orçamentária privilegiou o orçamento contínuo. Este tem como ênfase uma renovação do período concluído e acréscimo do mesmo período no futuro. A terceira fase foi o orçamento de base zero com a projeção dos recursos da estaca zero com justificativa para todos os gastos novos. A quarta etapa corresponde ao orçamento flexível que destaca a projeção dos recursos para vários níveis de atividade. Posteriormente, surgiu o orçamento por atividades. Este processo orçamentário é uma extensão do custeio baseado por atividades. O Orçamento por atividades apresenta projeção dos recursos nas atividades por meio dos direcionadores. O processo orçamentário mais recentemente elaborado é o Além do Orçamento - beyond budgeting. Este utiliza meios mais relativos e adaptáveis de planejamento, avaliação e controle de desempenho. É um modelo de gestão formado por um conjunto de princípios, os quais são guias de atuação empresarial.

\section{Custeio baseado em atividades}

O método de Custeio Baseado em Atividades - ABC foi divulgado por Robert S. Kaplan e Robin Cooper, professores da Harvard Business School no final da década de 1980. A metodologia proporciona alocação mais criteriosa dos custos indiretos a partir do conhecimento das atividades desenvolvidas na empresa (VANZELLA; LUNKES, 2006).

$\mathrm{O}$ ABC tem "como pressuposto que os recursos de uma empresa são consumidos por suas atividades e não pelos produtos que ela fabrica” (NAKAGAWA,1994, p.39).

$\mathrm{O}$ ABC consiste em identificar as atividades de uma empresa e atribuir custos a estas atividades, e destas para os produtos, diferenciando-se dos sistemas de custos tradicionais, pois esses rateiam os custos indiretos aos departamentos e produtos (VANZELLA; LUNKES, 2006).

Para que exista uma compreensão melhor do $\mathrm{ABC}$ torna-se necessário definir o que é atividade. Atividade é uma combinação de recursos humanos, materiais, tecnológicos e financeiros para se produzirem bens ou serviços, composta por um conjunto de tarefas necessárias ao seu 
desempenho (MARTINS, 1998).

Segundo Geishecker (1997) o ABC define três benefícios básicos.

-Primeiro benefício: ajuda a organização a obter mais e melhores informações sobre seus processos e atividades, o que permite que a eficiência das operações seja continuamente aumentada;

-Segundo benefício: a organização tem condições de racionalizar e otimizar a alocação de pessoal, capital e outros ativos;

-Terceiro benefício: torna-se mais ágil e voltada para o mercado, o que resulta numa posição mais competitiva.

O estabelecimento do montante de recursos consumidos pelas atividades é obtido pela utilização de direcionadores ou geradores de recursos. Para identificar os direcionadores se faz necessário conhecer os recursos que a empresa consome para posteriormente estabelecer quanto cada atividade consome destes recursos. O recurso consumido por cada atividade deve ser lançado na atividade que o consumiu, mas o recurso consumido por mais de uma atividade deve ser repartido entre as atividades que o consumiram. Essa é a função dos direcionadores de recursos, ou seja, medir a utilização dos recursos indiretos nas diversas atividades (VANZELLA; LUNKES, 2006).

\section{Orçamento baseado em atividades}

$\mathrm{O}$ orçamento baseado em atividades - $\mathrm{ABB}$, do inglês activity-based budgeting, é um plano financeiro e quantitativo que focaliza atividades e recursos com o intuito de atingir objetivos estratégicos (VANZELLA; LUNKES, 2006).

$\mathrm{O}$ ABB analisa os produtos e/ou serviços, na sequência verifica que atividades são exigidas para produzir esses produtos e/ou serviços, e quais recursos precisam ser orçados para executar essas atividades. Esse processo é o inverso do processo do Custeio Baseado em Atividades - ABC. No $\mathrm{ABB}$ refletem atividades e processos e não recursos como salários e materiais. Os recursos se originam das atividades esperadas, dos processos empresariais e da carga de trabalho. Assim, temse o número de unidades de uma atividade que é requerida. Vejamos um exemplo prático utilizado por Vanzella e Lunkes (2006) no departamento de recursos humanos a carga de trabalho para a atividade "contratar novos empregados" poderia ser contratar 50 empregados. Os recursos para executar aquela atividade poderiam ser os salários e benefícios do recrutador, viagem, propaganda, materiais, e despesas de ocupação para o espaço ocupado pelo recrutador e pelo entrevistado.

No orçamento baseado em atividades, a organização tem informações mais acuradas acerca do custo de seus produtos, bem como os orçamentos não serão elaborados com base nos valores dos períodos passados. Esses fatores geram valor para a organização. Não é obrigatório a utilização do 
ABC como sistema de custeio para a implantação do $\mathrm{ABB}$, embora seja o próximo passo lógico para quem já usa o $\mathrm{ABC}$, até porque ambos podem ser introduzidos simultaneamente. É possível que exista dependência de soluções de TI para o emprego do ABB, assim como ocorreu com o $\mathrm{ABC}$.

Conforme Vanzella e Lunkes (2006) é possível usar uma sequência de oito etapas para a formação do orçamento por atividades. Antes de se iniciar o processo torna-se necessário o conhecimento dos objetivos financeiros e do ponto de equilíbrio financeiro e operacional da empresa. As etapas iniciais podem ser repetidas quantas vezes forem necessárias até atingir o equilíbrio financeiro e operacional esperado.

Conforme Vanzella e Linkes (2006) as oito etapas do orçamento por atividades são dividas em três fases distintas: contextualização, preparação e revisão e aprovação.

-Contextualização: esta fase é o guia na elaboração do orçamento. Contempla a avaliação do ambiente operacional atual da organização, a atualização e planejamento do produto e do lucro de longo prazo para refletir as mudanças do ambiente, os objetivos do orçamento anual baseado no plano de longo prazo revisado e as previsões, metas e formatos exigidos a gerentes individuais com responsabilidade sobre o orçamento;

-Elaboração: a fase requer análises detalhadas e estimativas de atividades e recursos necessários para atender as atividades. $\mathrm{O}$ detalhamento também inclui a preparação e consolidação do orçamento individual da unidade em um formato de demonstração financeira. Embora baseado em dados históricos e expectativas futuras, os números gerados na fase de preparação devem ser "flexíveis"; e

-Revisão e aprovação: consiste em colocar a prova as previsões orçamentárias, com a finalidade de identificar problemas potenciais, definir o plano de ação e aprovar os limites para os gastos. Nessa fase são pedidas revisões do orçamento ou este é aprovado.

Brimson e Antos (1999) citam alguns benefícios do emprego do ABB:

-Delega responsabilidade aos funcionários na condução das atividades, a fim de atingir suas metas de desempenho;

-Apresenta visão realista do volume das atividades a serem desempenhadas, o que inclui os impactos nas alterações ao nível dessas atividades;

-Gera idéias acerca das origens de variações no processo produtivo, oriundos de exigências de clientes ou condições especiais de produtos ou serviços;

-Provê ferramentas necessárias para compreender como produtos e/ou serviços geram demanda por atividades específicas e que conduzem à identificação dos recursos necessários; 
-Incorpora visão de processo, que apresenta as interdependências entre os departamentos;

-Gera visibilidade para gerenciar o excesso ou a insuficiência da capacidade instalada.

Para ilustrar a importância do ABB vejamos o exemplo a seguir: Uma organização possui níveis estáveis de demanda de seus clientes, com utilização integral de sua força de trabalho, e, de repente, depara-se com uma retração de $40 \%$ na quantidade de pedidos e que esta queda seja permanente. A Figura 2 esclarece a situação, ao mostrar como o consumo dos recursos com pessoal refletiu, de imediato, a nova estrutura de custos da organização, e como ele se distanciou do gasto com esses mesmos recursos, que demoraram mais tempo para se adequar à nova realidade. Isto acontece porque, embora a organização possa se desfazer imediatamente de parte de sua mão de obra direta, gastos relativos a supervisores e pessoal administrativo necessitarão de algum tempo adicional para serem eliminados. Assim, o ABB provê, com seus direcionadores de custo, uma clara visualização desse tipo de problema (LOPES; BLASCHEK, 2007).

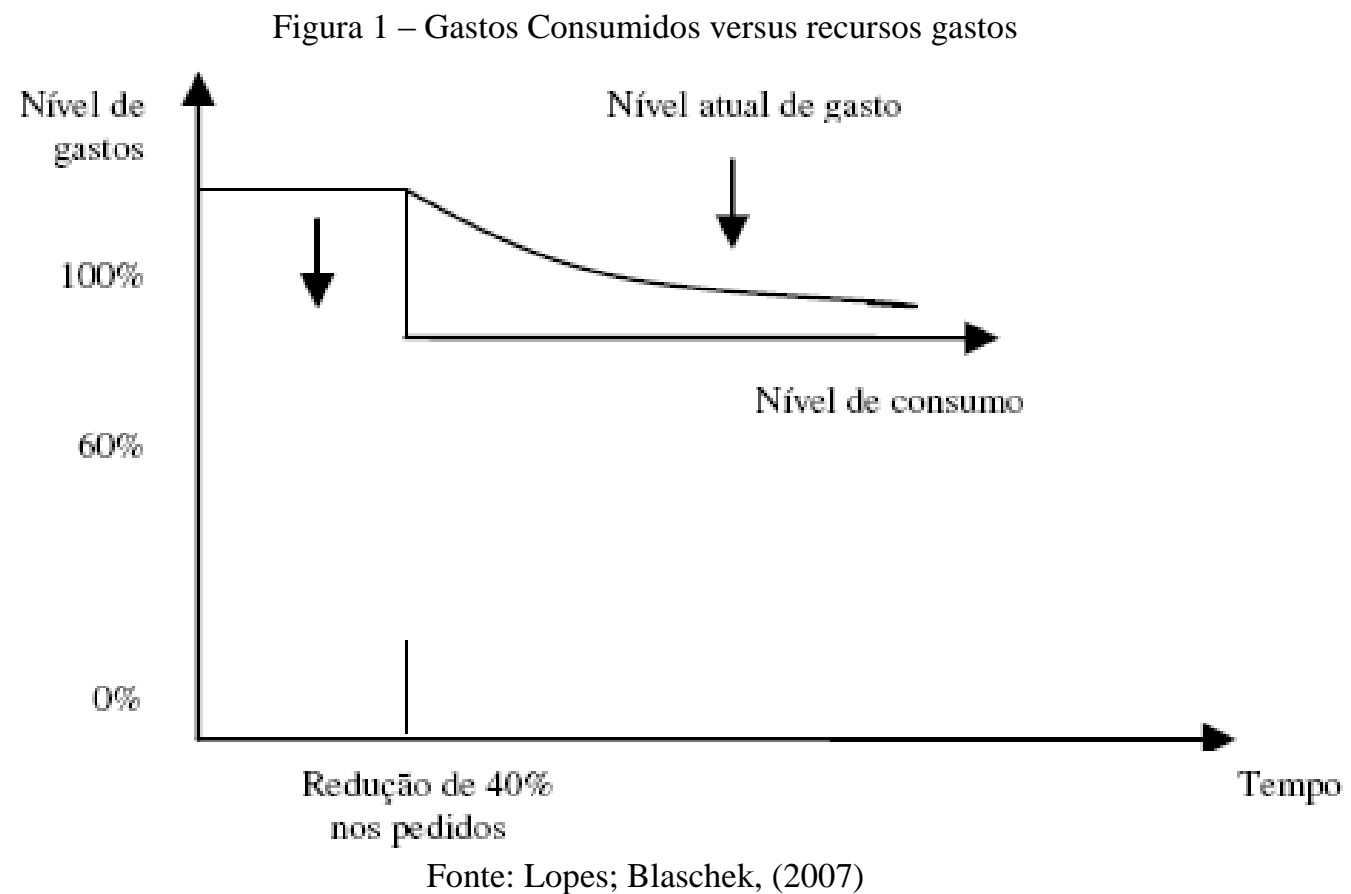

Para Lopes e Blaschek, (2007), o ABB identifica o nível de recursos necessários para executar as atividades, a relação entre essas atividades e o resultado obtido, e também como mudanças na expectativa dos resultados poderão afetar as atividades correlatas.

\section{Apresentação do caso}

Para ilustrar a interação do custeio baseado em atividades com o orçamento baseado em atividades, utilizaremos o caso da cervejeira denominada de " $\mathrm{X}$ " que quatro tipos de cervejas: Pilsen, Bock, München e Malzbier. O processo de fabricação e os dados coletados neste processo 
estão expressos a seguir.

Moagem do Malte: No Brasil, as indústrias cervejeiras preferem não utilizar malte de uma só procedência, mas, sim, uma mistura de diversos maltes com o objetivo de obter um mosto mais padronizado. A moagem do malte não deve ser muito fina a ponto de tornar lenta a filtragem do mosto ou, ao contrário, muito grossa, o que dificultaria a hidrólise do amido. A maior dificuldade provém de partículas finas de endosperma, proteína e de grãos de amido muito pequenos, como consequiência de grãos muito moídos.

A Filtração Após a açucaração da mistura há a clarificação do mosto com a sedimentação natural do bagaço, uma massa resultante da aglutinação da casca com resíduos do processo. A remoção do mosto limpo é efetuado por gravidade através do bagaço nas tinas de filtração, que possuem fundo falso tipo peneira. Pode ser feita ainda em filtros, prensas e através de panos de algodão ou nylon

A Fermentação: Consiste na decomposição dos açúcares fermentáveis do mosto em álcool e gás carbônico pela ação da levedura. O levedo produz álcool e gás carbônico ao dissociar os açúcares fermentáveis alimentando-se, ao mesmo tempo, de proteínas, sais minerais e alguns açúcares.

Maturação: Consiste no armazenamento da cerveja fermentada a baixa temperatura durante um determinado período de tempo. Uma lenta fermentação ocorre na cerveja, proporcionando a clarificação por precipitação de leveduras e proteínas, assim como de sólidos solúveis. Além destas, ocorrem alterações químicas que auxiliam a clarificação e melhoram o aroma e sabor.

Envasamento: A cerveja acondicionada em latas e garrafas é esterilizada por pasteurização. A pasteurização da cerveja envasada é realizada em túneis onde a temperatura é elevada à $60^{\circ} \mathrm{C}$ e mantida nessa temperatura até garantir a morte dos microorganismos deterioradores. Em seguida, sofre um drástico resfriamento. A cerveja em barris, denominada chope, não é pasteurizada e, por isso, deve ser armazenada a baixa temperatura em recipiente de aço inoxidável, alumínio ou madeira, de volume variável e ainda assim, tem conservação limitada.

As informações coletadas no orçamento baseado em atividades e utilizadas para a elaboração do custo do produção foram as seguintes:

Tabela 2 - Produtos e Custos Diretos

\begin{tabular}{l|llll}
\hline Produtos & Origem & Teor Alcoólico & Quantidade Produzida $(l)$ & Custo Direto \\
\hline Pilsen & Rep. Checa & Médio & 100.000 & 0,45 \\
Bock & Alemanha & Alto & 15.000 & 0,48 \\
München & Alemanha & Médio & 8.000 & 0,44 \\
\hline Malzbier & Alemanha & Alto & 50.000 & 0,49 \\
\hline
\end{tabular}

Fonte: Dados da pesquisa 
Posteriormente se faz necessário identificar o total de gastos por cada atividade do processo de fabricação dos bens.

Tabela 3 - Custos Indiretos por Atividade

\begin{tabular}{l|lllll}
\hline Custos Indiretos / Atividade & Moagem & Filrtação & Fermentação & Maturação & Envase \\
\hline Total & $59.000,00$ & $28.500,00$ & $39.500,00$ & $14.000,00$ & $38.000,00$ \\
\hline
\end{tabular}

Fonte: Dados da pesquisa

Com a definição dos custos indiretos a outra informação necessária para o cálculo do custo do produto são os direcionadores de custos por atividade.

Tabela 4 - Direcionadores de Custos

\begin{tabular}{l|lcccc}
\hline Atividades/Direcionadores & Moagem & Filrtação & Fermentação & Maturação & Envase \\
\hline Pilsen & $1.000 .000,00$ & $500.000,00$ & $2.500 .000,00$ & $4.500 .000,00$ & $10.000,00$ \\
Bock & $150.000,00$ & $75.000,00$ & $300.000,00$ & $675.000,00$ & $1.500,00$ \\
München & $80.000,00$ & $40.000,00$ & $160.000,00$ & $360.000,00$ & 800,00 \\
Malzbier & $500.000,00$ & $250.000,00$ & $1.000 .000,00$ & $2.650 .000,00$ & $5.000,00$ \\
\hline Total da Atividade & $1.730 .000,00$ & $865.000,00$ & $3.960 .000,00$ & $8.185 .000,00$ & $17.300,00$ \\
\hline Fon & & & & & \\
\hline
\end{tabular}

Fonte: Dados da pesquisa

Com a definição das atividades e dos valores orçamentários, a primeira etapa consiste em verificar o total de custos indiretos alocados orçamentariamente para cada atividade da organização e verificar também a quantidade que cada atividade é exercida no período analisado. Desta forma pode-se obter o custo unitário indireto para cada atividade orçamentária estabelecida no ABB

Tabela 5 - Custo Indireto Unitário por Atividade

\begin{tabular}{l|llccc}
\hline Base de Rateio & Moagem & filtração & Fermentação & Maturação & Envase \\
\hline Custos indiretos & & & & \\
& $59.000,00$ & $28.500,00$ & $39.500,00$ & $14.000,00$ & $38.000,00$ \\
$\mathrm{~N}^{\circ}$ de vezes Atividade & $1.730 .000,00$ & $865.000,00$ & $3.960 .000,00$ & $8.185 .000,00$ & $17.300,00$ \\
Custo unitário indireto & 0,03410 & 0,03295 & 0,00997 & 0,00171 & 2,19653 \\
\hline
\end{tabular}

Fonte: Dados da pesquisa

Para a definição do custo indireto unitário por atividade dividimos o custo indireto de cada atividade pelo direcionador de custo, ou seja, quantas vezes que cada atividade foi realizada.

Com a definição do custo da atividade fica possível identificar a alocação de custo indireto unitário para cada produto.

Tabela 6 - Custos Indiretos por produto na Atividade moagem

\begin{tabular}{l|llll}
\hline Moagem & Pilsen & Bock & München & Malzbier \\
\hline
\end{tabular}




\begin{tabular}{l|lllr}
\hline $\mathrm{N}^{\circ}$ de vezes & $1.000 .000,00$ & $150.000,00$ & $80.000,00$ & $500.000,00$ \\
Custo unitário & 0,03410 & 0,03410 & 0,03410 & 0,03410 \\
Custo alocado & $34.104,05$ & $5.115,61$ & $2.728,32$ & $17.052,02$ \\
Produção & $100.000,00$ & $15.000,00$ & $8.000,00$ & $50.000,00$ \\
Custo Unitário & 0,34104 & 0,34104 & 0,34104 & 0,34104 \\
\hline
\end{tabular}

Fonte: Dados da pesquisa

Para se definir o quanto de custo indireto da atividade de moagem deve ser distribuída para cada produto devemos multiplicar o direcionador de custos de cada produto pelo custo unitário da atividade, assim encontramos o total de custo alocado para cada produto. Para encontrar o custo indireto unitário da atividade de moagem para cada produto basta dividir o custo alocado pela produção de item.

Na sequência repete-se o cálculo para as demais atividades.

Tabela 7 - Custos Indiretos por produto na Atividade filtração

\begin{tabular}{l|llll}
\hline Filtração & Pilsen & Bock & München & Malzbier \\
\hline $\mathrm{N}^{\circ}$ de vezes & $500.000,00$ & $75.000,00$ & $40.000,00$ & $250.000,00$ \\
Custo unitário & 0,03295 & 0,03295 & 0,03295 & 0,03295 \\
Custo alocado & $16.473,99$ & $2.471,10$ & $1.317,92$ & $8.236,99$ \\
Produção & $100.000,00$ & $15.000,00$ & $8.000,00$ & $50.000,00$ \\
Custo Unitário & 0,16474 & 0,16474 & 0,16474 & 0,16474 \\
\hline
\end{tabular}

Fonte: Dados da pesquisa

Tabela 8 - Custos Indiretos por produto na Atividade fermentação

\begin{tabular}{l|lccc}
\multicolumn{5}{c}{ Tabela 8-Custos Indiretos por produto na Atividade fermentação } \\
\hline Fermentação & Pilsen & Bock & München & Malzbier \\
\hline $\mathrm{N}^{\circ}$ de vezes & $2.500 .000,00$ & $300.000,00$ & $160.000,00$ & $1.000 .000,00$ \\
Custo unitário & 0,00997 & 0,00997 & 0,00997 & 0,00997 \\
Custo alocado & $24.936,87$ & $2.992,42$ & $1.595,96$ & $9.974,75$ \\
Produção & $100.000,00$ & $15.000,00$ & $8.000,00$ & $50.000,00$ \\
Custo Unitário & 0,24937 & 0,19949 & 0,19949 & 0,19949
\end{tabular}

Fonte: Dados da pesquisa

Tabela 9 - Custos Indiretos por produto na Atividade maturação

\begin{tabular}{l|llll}
\hline Maturação & Pilsen & Bock & München & Malzbier \\
\hline $\mathrm{N}^{\circ}$ de vezes & $4.500 .000,00$ & $675.000,00$ & $360.000,00$ & $2.650 .000,00$ \\
\multirow{2}{*}{ Custo unitário } & & 0,00171 & 0,00171 & 0,00171 \\
\hline
\end{tabular}




\begin{tabular}{l|lccc}
\hline Custo alocado & & & & \\
Produção & $7.697,01$ & $1.154,55$ & 615,76 & $4.532,68$ \\
& $100.000,00$ & $15.000,00$ & $8.000,00$ & $50.000,00$ \\
Custo Unitário & 0,07697 & 0,07697 & 0,07697 & 0,09065 \\
\hline
\end{tabular}

Fonte: Dados da pesquisa

Tabela 10 - Custos Indiretos por produto na Atividade envase

\begin{tabular}{l|lccc}
\hline Envase & Pilsen & Bock & München & Malzbier \\
\hline $\mathrm{N}^{\circ}$ de vezes & $10.000,00$ & $1.500,00$ & 800,00 & $5.000,00$ \\
Custo unitário & 2,19653 & 2,19653 & 2,19653 & 2,19653 \\
Custo alocado & $21.965,32$ & $3.294,80$ & $1.757,23$ & $10.982,66$ \\
Produção & $100.000,00$ & $15.000,00$ & $8.000,00$ & $50.000,00$ \\
Custo Unitário & 0,21965 & 0,21965 & 0,21965 & 0,21965 \\
\hline
\end{tabular}

Fonte: Dados da pesquisa

Com todos os custos indiretos das atividades atribuídos aos produtos, basta somar os custos diretos aos indiretos. Lembrando que os custos indiretos são as somas dos custos indiretos unitários para cada uma das cinco atividades identificadas.

\begin{tabular}{|c|c|c|c|c|}
\hline & Pilsen & Bock & München & Malzbier \\
\hline \multirow[t]{2}{*}{ Custo Indireto } & & & & \\
\hline & 1,05 & 1,00 & 1,00 & 1,02 \\
\hline Custo Direto & 0,45 & 0,48 & 0,44 & 0,49 \\
\hline Custo Produto & 1,50 & & & \\
\hline
\end{tabular}

Fonte: Dados da pesquisa

Definidas as atividades, direcionadores de recursos e de atividades, um sistema ABC pode ser implantado, bem como um Orçamento Baseado em Atividades. Como o custeio já foi descrito, agora passaremos ao orçamento.

O primeiro passo é contextualizar o orçamento por atividades. Para efeito de ilustração, a empresa prevê aumento salarial para os empregados e aumentos nos índices de preços de materiais e serviços, é preciso considerá-los ao quantificar monetariamente os direcionadores. De posse das informações sobre aumento das vendas e estratégias empresariais se torna possível elaborar o orçamento por atividades.

O primeiro passo é determinar a demanda projetada. Para este estudo, supõe-se aumento de 5\% nas vendas de litros de cerveja. O segundo passo consiste na identificação das atividades e seus direcionadores, bem como as taxas de consumo dos mesmos. No terceiro passo, é preciso estabelecer a demanda total do consumo da atividade. Assim, se haverá aumento de $5 \%$ nas vendas, 
a quantidade de direcionadores por objeto de custo será conforme a tabela a seguir. A tabela também mostra a quantidade de recursos realizados em período anterior.

\begin{tabular}{l|ll}
\multicolumn{3}{c}{ Tabela 12 - Direcionador de consumo de litros } \\
\hline Produtos & Litros Consumidos realizado & Litros Consumidos orçados \\
\hline Pilsen & 100.000 & 98.543 \\
Bock & 15.000 & 15.122 \\
München & 8.000 & 8.830 \\
\hline Malzbier & 50.000 & 50.231 \\
\hline
\end{tabular}

Fonte: Dados da pesquisa

Para concretizar um volume superior de vendas, a empresa necessita prever a demanda das atividades, ou seja, identificar quais atividades são necessárias para fornecer os produtos. Esta é a quarta etapa, e devem ser identificadas todas as atividades primárias (ou operacionais) e secundárias (de apoio), necessárias ao fornecimento dos produtos e funcionamento da empresa.

No quinto passo é identificar os direcionadores de recursos. Observe que o direcionador de recursos foi identificado já no custeio, na tabela 3.

O sexto passo consiste em multiplicar o total das atividades requeridas com as taxas dos recursos consumidos para calcular a quantidade de recursos necessários para satisfazer as demandas projetada para o objeto de custo. Na sequência, como sétimo passo, se faz necessário converter o total dos recursos requeridos (quantidade) com o custo dos recursos exigidos

Tabela 13 - Novos gastos considerando aumento de $5 \%$ nas vendas

\begin{tabular}{l|lllll}
\hline Custos Indiretos / Atividade & Moagem & Filrtação & Fermentação & Maturação & Envase \\
\hline Total & $61.300,00$ & $29.400,00$ & $41.000,00$ & $14.400,00$ & $39.500,00$ \\
\hline
\end{tabular}

Fonte: Dados da pesquisa

Conforme pode ser observado por meio da tabela 12, o orçamento prevê aumento de, aproximadamente, 3,7\% (três vírgula sete por cento) nos custos. Em contrapartida, há previsão de aumento de 5\% (cinco por cento) nas vendas. A diferença representa um ganho para a empresa.

Por fim, no oitavo passo, é preciso mostrar a acumulação do custo total dos recursos para atender à demanda projetada, ou seja, após quantificados os direcionadores em todas as unidades, e projetado o custo total do direcionador de cada unidade, é preciso somar os recursos para se obter o total orçado da organização.

\section{Conclusão}

Nenhum sistema de orçamento ou de planejamento pode esperar resolver todos os problemas administrativos. 
Nos orçamentos tradicionais, geralmente não há metas bem definidas e o envolvimento na elaboração do orçamento, restringe-se apenas a alta administração, ou seja, não há uma participação efetiva dos funcionários da empresa. Essas projeções sempre são feitas considerando-se os orçamentos dos anos anteriores e isso normalmente gera como resultado as mesmas falhas e perpetuação dos erros.

$\mathrm{O}$ orçamento baseado em atividades analisa os produtos ou serviços produzidos, que atividades são exigidas para produzir esses produtos ou serviços, e que recursos precisam ser orçados para executar essas atividades.

A realização do estudo de caso, embora com números simplificados, permitiu verificar que o ABB pode ser aplicado a todas as atividades da empresa analisada. Também foi possível verificar que a diferença entre o orçamento tradicional e o $\mathrm{ABB}$ reside no fato do consumo dos recursos ocorrer por atividades, enquanto naquele os recursos são consumidos pelos centros de custos. Ressalta-se que o ABB foi apresentado para cinco atividades agregadoras de valor e que estavam sendo executadas eficientemente. Cabe ressaltar que, na implantação do orçamento por atividades é imprescindível a participação da gerência e empregados. O sucesso na operacionalização da metodologia depende da disponibilidade de meios e recursos necessários para a sua implantação, assim como da superação da resistência inicial à sua adoção.

Assim, este modelo orçamentário utiliza meios mais relativos e adaptáveis de planejamento, avaliação e controle de desempenho. É um modelo de gestão formado por um conjunto de princípios, os quais são guias de atuação empresarial.

\section{Abstract}

The objective of this paper is to show the interaction of activity-based costing to budget based on activities evidencing a case study in the industrial sector, a case study in a brewery. The budget based on activities examines the goods or services produced, what activities are required to produce those goods or services, and what resources need to be budgeted to perform these activities. The completion of the case study, albeit with simplified figures, showed that the activity-based budget can be applied to all activities of the company analyzed. It was also observed that the difference between the traditional budget and budget based on activities lies in the fact that the consumption of resources by activities occurring while that resources are consumed by the cost centers.

Key-words: activity-based budgeting, activity based costing, industry.

\section{Referências}

BORNIA, A. C.; LUNKES, R. J. Uma Contribuição à Melhoria do Processo Orçamentário. Contabilidade Vista \& Revista. v.18, n.4, p.37-59 out/dez. 2007.

GEISHECKER, Mary Lee. Tecnologia melhora o ABC. HSM. São Paulo, ano 1, n. 5, p. 20-21, 1997

HANSEN, S. C.; OTLEY, D. T.; STEDE, W. A. V. D. Practice developments in budgeting: an overview and research perspective. Journal of management accounting research. v. 15, p 95-116, 2003. 
JOHNSON, T. H.; KAPLAN, R. S. Relevance lost. Boston: Harvard Business School Press, 1987.

LOPES; BLASCHEK. Minimizando as Deficiências do Planejamento Operacional com o Uso do Orçamento Baseado em Atividades. Revista de Contabilidade do Mestrado em Ciências Contábeis da UERJ, Rio de Janeiro, v.12, n.2, maio/ago, 2007.

LUNKES, R. J. Manual de orçamento. 2. ed. São Paulo: Atlas, 2007.

MARTINS, E. Contabilidade de custos. 6. ed. São Paulo: Atlas, 1998.

NAKAGAWA, M. ABC. São Paulo: Atlas, 1994.

TAVARES, M.C. Planejamento estratégico: a opção entre sucesso e fracasso empresarial. São Paulo: Harbra, 1991

VANZELLA, C; LUNKES, R. J. Orçamento Baseado em Atividades: um estudo de caso. Contab. Vista \& Rev., v. 17, n. 1, p. 113-132, jan./mar. 2006

ZDANOVICZ, J. E. Orçamento Operacional: Uma Abordagem Prática. 3.ed. Porto Alegre, Sagra, 1989.

\section{Dados dos autores:}

Nome completo: Thiago Coelho Soares

Filiação institucional: Professor da Unisul.

Departamento: Administração.

Função ou cargo ocupado: Coordenador do programa de pós-graduação em gestão empresarial da UnisulVirtual.

Endereço completo para correspondência (bairro, cidade, estado, país e CEP): Av. dos Lagos, 41 Pedra Branca, Palhoça/SC - 88137-100.

Telefones para contato: (48) 3279-1308

e-mail: thiago.soares@unisul.br

Enviado em: 21/12/2010

Aprovado em: 27/09/2011 